\title{
Electromagnetic processes of charging of on-board supercapacitor storage system during the regenerative braking mode of DC electric rolling stock with series-wound DC motors
}

\author{
Anatolii Nikitenko ${ }^{1, *}$ \\ ${ }^{1}$ Warsaw University of Technology, Institute of Electric Power Engineering, Electric Traction Division, \\ ul. Koszykowa 75, 00-662, Warsaw, Poland
}

\begin{abstract}
The paper is dedicated to the task of improving of regenerative braking of a DC train with the series-wound DC traction motors. It is proposed the schematic solution for the trains with DC motors, which is based on the storing of recovered energy by the on-board supercapacitor storage system and extending the speed range of regenerative braking. The scheme is described by expressions which allowed to build the time dependences of main values. In addition, the experimental researches with the multiple-unit train were performed to find initial data for calculations and verification the results. The transient processes of charging are analyses for different cases of storage capacitances, residual voltages and initial speed of braking. It was proved, that the scheme allows to increase the value of recovered energy up to $40 \%$, but its value strongly depends on the initial conditions and parameters of the system.
\end{abstract}

\section{Introduction}

About $36 \%$ of electrified railway lines are supplied by 3 or $1.5 \mathrm{kV}$ DC voltage. As much as $47000 \mathrm{DC}$ supplied electric locomotives are currently in use in the world. Many of them, among others in East European countries, still equipped with the series-wound DC motors and rheostatic control due to long life time, comparatively low price, simple design of control system and selfexcitation of the field coils [1]. On the other hand, they have numerous disadvantages, designed without regenerative braking or cannot use it due to the frequent faults, which appear in the process of real operation [2]. Therefore, the train drivers frequently have no choice and apply the rheostat braking to reduce the high speed of the vehicle, so the recovered (kinetic) energy is uselessly dissipated in the ballast resistors. Furthermore, the experimental researches of [3] show that the losses of recovered energy in the overhead contact system vary from 6.3 to $20 \%$ in case of transmission to the train which operates in traction mode. The losses are equal to $1.5 \div 43.1 \%$ when the recovered energy flows to the traction substation and is inverted to $\mathrm{AC}$ grid. Thus, the task of improvement of effectiveness of regenerative braking stays actual for railway vehicles with $\mathrm{AC}$ and DC traction. It is a current issue specifically in East and Central European countries with DC supplied railway when thousands of old-type rolling stock with DC motors and rheostatic control are being in use. The problem can be solved by development of the new autonomous from power supply system recuperative braking modes with the application of energy storage systems based on supercapacitor, batteries, flywheel or mixed. Undoubtedly, in recent years the supercapacitors with high capacitances have become very popular due to a low weigh and dimensions, high power density, a large number of charge-discharge cycles, long operating lifetime and comparatively short payback period. This leads to numerous researches of the stationary $[4,5]$ or onboard storage systems [6-12] in the urban transport. Nevertheless, review of the published researches shows that all of them are dedicated to the electric vehicles with $\mathrm{AC}$ traction motors. The only few researches are dedicated to the electric vehicles with DC traction motors.

\section{An overview of associated researches}

[6] proposes the method of proper sizing of on-board supercapacitor energy storage system for catenary-free operations of a tram. It is based on the measurements made in the process of operation of empty experimental tram vehicle to estimate power and energy losses and find optimal size of the storage. It is equal to $0.75 \div 3$ $\mathrm{kWh}$ and allows to overcome the distance of $1 \mathrm{~km}$ with the slope of $0 \div 1 \%$.

The author [7] presents a control strategy for improving the energy recovery of AC traction drives and describes the results of simulation of a railway vehicle equipped with on-board supercapacitor storage system, which is based on Maxwell supercapacitor module of HTM390 type. The control strategy was verified on a physical model and it was established that supercapacitors on the board of train allow to reduce the line current over the $50 \%$. The same result is shown in [8-13]. Furthermore, [8] compares different types of storages and shows the

\footnotetext{
* Corresponding author: anatolij.nikitenko@ien.pw.edu.pl
} 
results of experimental research with a prototype of light railway vehicle GT6N equipped with Mitrac energy saver. The system allows to achieve the energy saving of up to $30 \%$. But all these researches are dedicated to electric vehicles with AC motors, accept of [10-13].

[10] investigates different types of electrical vehicles with supercapacitor storages. There are trolleybus Jelcz $M 121 E$ and the $116 \mathrm{~N}$ tram with DC motors. The storage allows to reduce the energy consumption on $0.9 \mathrm{kWh} / \mathrm{km}$ and nearly $30 \%$ of consumed energy. The estimated payback period equals $7 \div 8$ years. At the same time, it should be pointed out, that according experimental investigation in [4] the life expectancy of supercapacitor storages equals 15 years.

The researches of the DC trams of Tatra T3A with DC motors are performed in $[11,12]$. They describe the prospects of use and modernization of railway vehicles with DC traction motors. The main schematic solutions and results of simulation are shown. The storage allows to store efficiently all the energy recovered during the braking.

In [13] the development of the regenerative braking of series-wound brushed DC electric motors is shown. The main reason is the widely usage of series-wound configuration in electrical vehicles and industry. It compares two schemes, shows semantical solutions with full-bridge modification and results of simulation for the DC motor of FB1-4001 type, which is used in electric cars.

But all mentioned researches are dedicated to the urban vehicles (metro cars, trams, trolleybuses) and, at the moment, there are no publications which investigate the application of on-board storages in sub-urban trains.

\section{Behaviours of regenerative braking of DC ERS with on-board storage}

The application of energy storage system on the board of DC electric rolling stock (ERS) may improve the electrical effectiveness of regenerative braking and, simultaneously, stipulates the behaviours of electromagnetic transient processes, which run in the traction power circuits in the charge-discharge modes of the storage. These behaviours are caused by different factors. Firstly, peculiarity of charge-discharge cycles. Their parameters and thus the parameters of the elements of power circuit are changing in wide rage. Secondly, numerous types of the DC ERS apply the regenerative braking mode only till the speed of $51 \div 49 \mathrm{~km} / \mathrm{h}$. The initial speed of the application of regenerative braking mode is equal to $74 \div 62 \mathrm{~km} / \mathrm{h}$, in singular case $91 \div 88$ $\mathrm{km} / \mathrm{h}$. Such speed range of regenerative braking is very low and it should be extended till the speed $20 \mathrm{~km} / \mathrm{h}$ or $10 \div 5 \mathrm{~km} / \mathrm{h}$ when the mechanical braking is applicable [2]. This purpose allows to increase the effectiveness of the recovered (kinetic) energy use and may to be achieved with the application of on-board supercapacitor storage system (SSS). Thirdly, in the process of starting up or acceleration the voltage of ERS arises in proportion to the speed, when the voltage of SSS falls down within its recharging. Finally, in the regenerative braking mode (RBM) the speed reduces and thus the total voltage of motors falls down too. But the voltage of
SSS increases in proportion to the braking current and the time duration of its flowing. All these behaviours make the analysis of electromagnetic transient processes more complicated and keep finding the alternative approaches for their investigation.

\section{Behaviours of regenerative braking of DC ERS with on-board storage}

The main purpose of electromagnetic processes investigation is the defining of time dependences of braking current $i(t)$ in the traction electric motors (TEM) and voltage $u_{C}(t)$ across the SSS. The defining and support of braking current constancy is especially important so long as it is necessary to keep in the constant value of the braking force.

The principal scheme of the regenerative braking with the on-board SSS is shown in Fig. 1 for an DC multiple-unit train (as yet without input and output filters), where Sw1 is a pulse controller-interrupter; Sw2 and Sw3 are the voltage and current pulse controllers (switches).

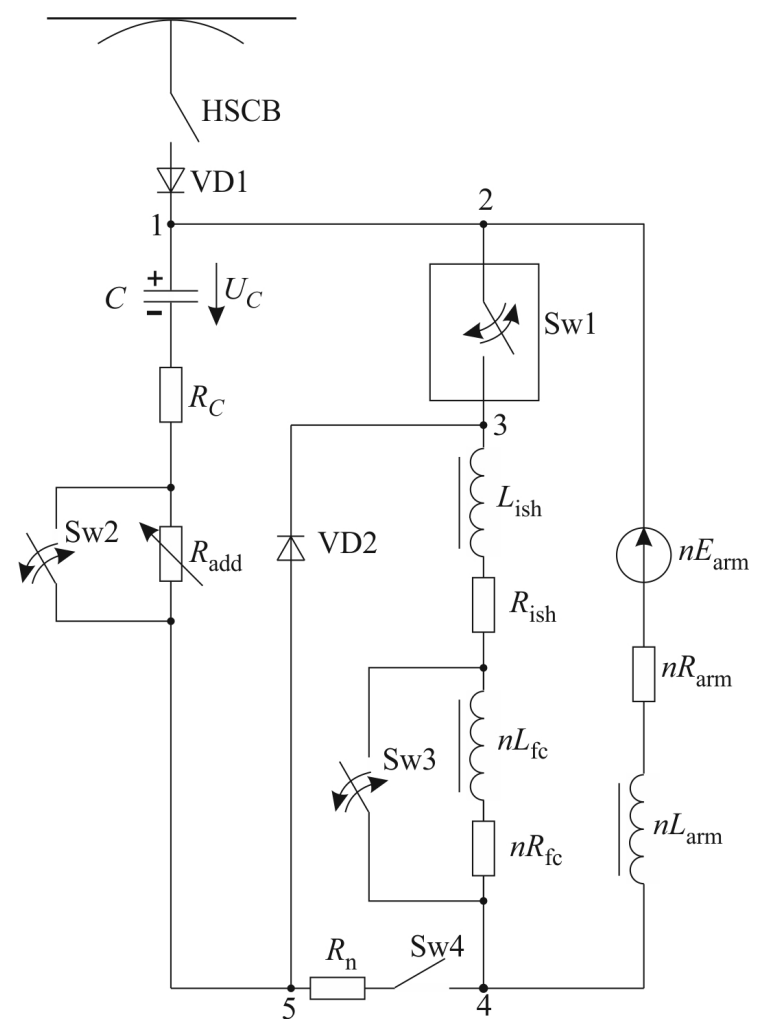

Fig. 1. Principal scheme of the on-board SSS charging.

Let us assume the next conditions for calculation and analysis of the transient processes:

- the inductances of TEMs and inductive shunt are constant values;

- the diodes VD1 and VD2 are an ideal;

- the controllers Sw1, Sw2 and Sw3 operate instantaneously;

- a rotary speed is a constant at the moments of controllers' operation, because the armatures have considerable inertia masses;

- the pulse controllers are changed by switches;

- a self-excitation stage of TEMs has been finished. 


\subsection{The first stage - zone of high speeds}

Let accept that in the high speeds (over $50 \mathrm{~km} / \mathrm{h}$ ) the TEMs' magnet systems operate in the linear part of normal magnetization curve $C_{\mathrm{e}} \Phi\left(I_{\mathrm{fc}}\right)$ within the range from an initial (maximal) speed $V_{\text {in }}$ till a final speed $V_{\mathrm{fn} 1}$. In the period of speed decreasing the pulse controller Sw3 holds the constancy of armatures' emfs $n E_{\text {arm }}$ of $n$ traction motors connected in series. The braking (charging) current $i(t)$ is kept in constancy by the additional resistance $R_{\text {add }}(t)$ using pulse controller Sw2. According to calculating scheme in Fig. 2 and taking into account that the braking current $i(t)$ equals the currents in the armature $i_{\text {arm }}(t)$ and in the field coil $i_{\mathrm{fc}}(t)$, the equation for the first charging stage may to be written as

$u_{C}(t)+\left(R_{\Sigma}+R_{\text {add }}(t)\right) \cdot t(t)+L_{\Sigma} \frac{d i}{d t}=n E_{\text {arm }}=E_{\text {gen }}=$ const, (1)

where $R_{\Sigma}=n \cdot\left(R_{\mathrm{arm}}+R_{\mathrm{fc}}+R_{\mathrm{cw}}\right)+R_{\mathrm{ish}}+R_{C}=$

$=n R_{\mathrm{TEM}}+R_{\mathrm{ish}}+R_{C}$;

$L_{\Sigma}=n \cdot\left(L_{\mathrm{arm}}+L_{\mathrm{fc}}+L_{\mathrm{cw}}\right)+L_{\mathrm{ish}}=n L_{\mathrm{TEM}}+L_{\mathrm{ish}}$;

$E_{\text {arm }}, R_{\text {arm }}, L_{\text {arm }}$ - emf, resistance and inductance of the armature;

$E_{\text {gen }}$ - total generated emf;

$R_{\mathrm{fc}}, L_{\mathrm{fc}}-$ resistance and inductance of the field coil;

$R_{\mathrm{cw}}, L_{\mathrm{cw}}$ - resistance and inductance of the commutating winding;

$R_{\text {ish }}, L_{\text {ish }}$ - resistance and inductance of the inductive shunt;

$R_{C}$-internal resistance of supercapacitor storage.

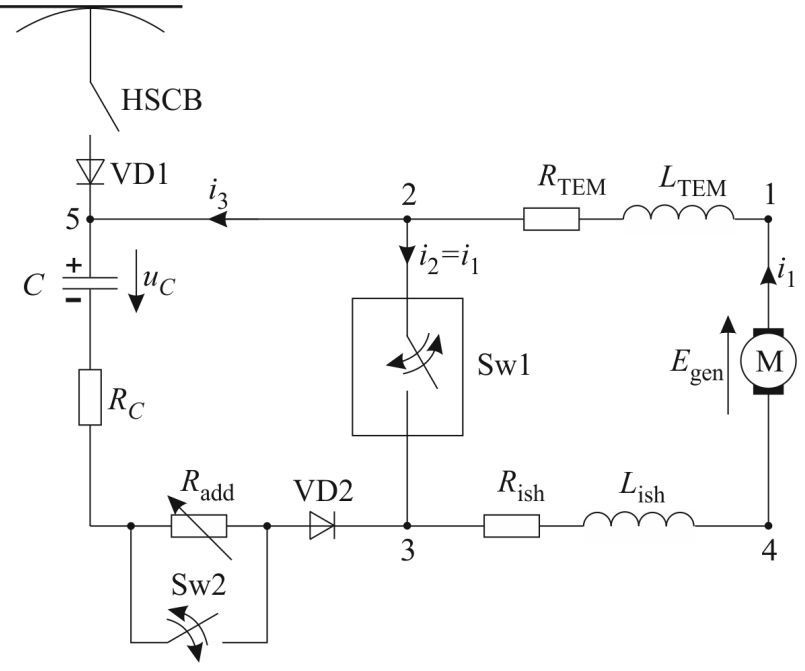

Fig. 2. Calculating scheme of impulse transmission of electric energy to SSS.

As for as $i(t)=C^{d u_{C}} / d t$ the equation may to be rewritten as

$$
\begin{gathered}
\frac{d^{2} u_{C}}{d t}+\frac{R_{\Sigma}+R_{\mathrm{add}}(t)}{L_{\Sigma}} \cdot \frac{d u_{C}}{d t}+\frac{1}{L_{\Sigma} \cdot C}= \\
=n E_{\mathrm{arm}}=E_{\mathrm{gen}}=\text { const },
\end{gathered}
$$

which have to be solved for a certain value of initial condition $u_{C}(0)=U_{C 0}$.

Let us calculate (2) for a speed $V$ and find the expression of $u_{C}(t)$ for the charging mode using Classical approach [14] as

$$
u_{C}(t)=u_{C \mathrm{st}}(t)+u_{C \mathrm{fr}}(t) .
$$

As far as $E_{\text {gen }}(V)$ is an invariable in this stage, thus the voltage $u_{C \mathrm{st}}(t)$ for a steady-state mode is

$$
u_{C s t}(t)=E_{\text {gen }}=C_{\mathrm{e}} \Phi \cdot V(t)=C_{\mathrm{e}} \Phi \cdot V .
$$

According to Fig. 2 the free component $u_{C f r}(t)$ of the voltage for a general case is

$$
u_{C \mathrm{fr}}(t)=A_{1} e^{p_{1} t}+A_{2} e^{p_{2} t} .
$$

As for as $R_{\Sigma}>R_{\text {critical }}=2 \sqrt{L_{\Sigma} / \mathrm{C}}$, so the roots $p_{1}$ and $p_{2}$ are negative and have to be found as

$$
p_{1,2}=-\frac{R_{\Sigma}+R_{\mathrm{add}}(t)}{2 L_{\Sigma}} \pm \sqrt{\frac{R_{\Sigma}+R_{\mathrm{add}}(t)}{4 L_{\Sigma}}-\frac{1}{L_{\Sigma} C}} .
$$

Let find the integrating constants $A_{1}$ and $A_{2}$. Substitute (4) and (5) into (3) and derive it by $t$ as

$$
\left\{\begin{array}{l}
u_{C}(t)=E_{g e n 0}+A_{1} e^{p_{1} t}+A_{2} e^{p_{2} t}, \\
\frac{d u_{C}}{d t}=0+A_{1} p_{1} e^{p_{1} t}+A_{2} p_{2} e^{p_{2} t} .
\end{array}\right.
$$

After solving of (7), the voltage $u_{C}(t)$ and the current $i_{3}(t)=C \frac{d u_{C}}{d t}$ in the first stage of charging have to be found according the expressions:

$$
\begin{gathered}
u_{C}(t)=E_{\mathrm{gen} 0}+\frac{\left(E_{\mathrm{gen} 0}-U_{C 0}\right) p_{2}}{p_{1}-p_{2}} e^{p_{1} t}-\frac{\left(E_{\mathrm{gen} 0}-U_{C 0}\right) p_{1}}{p_{1}-p_{2}} e^{p_{2} t}, \\
i_{3}(t)=i_{1}(t)=\frac{E_{\mathrm{gen} 0}-U_{C 0}}{L_{\Sigma}\left(p_{1}-p_{2}\right)} e^{p_{1} t}-\frac{E_{\mathrm{gen} 0}-U_{C 0}}{L_{\Sigma} \cdot\left(p_{1}-p_{2}\right)} e^{p_{2} t} .
\end{gathered}
$$

\subsection{The second stage - zone of middle and low speeds}

In the previous stage the TEMs' magnet systems reach the full-field mode ( $C_{\mathrm{e}} \Phi=$ const $)$ till the speed $V_{\text {fn1 }}$. As for as the speed continues decreasing till the speed $V_{\mathrm{fn} 2}$, the total emf also reduces and it can't be corrected by the current $I_{\mathrm{fc}}$ of field coil, therefore the impulse mode of RBM should be applied on the second stage.

According Fig. 2 the regenerative braking operates with short switching on of TEMs by controller Sw1. As a result, the braking current $i_{1}(t)$ flows in the loop 1-23-4 and the equation of this mode may to be written as

$$
\begin{aligned}
\left(n \cdot R_{\mathrm{TEM}}+\right. & \left.R_{\mathrm{ish}}\right) \cdot i_{1}(t)+\left(n \cdot L_{\mathrm{TEM}}+L_{\mathrm{ish}}\right) \cdot \frac{d i_{1}}{d t}= \\
& =E_{\mathrm{gen}}(t)=n \cdot C_{\mathrm{e}} \Phi \cdot V(t) .
\end{aligned}
$$

Using Classical approach [14] with initial data $i_{1}(0)=i_{3}(0)=I_{02}$, the equation of current $i_{1}(t)$ is 
$i_{1}(t)=\frac{n \cdot C_{\mathrm{e}} \Phi \cdot V(t)}{n \cdot R_{\mathrm{TEM}}+R_{\mathrm{ish}}}+\left[I_{02}-\frac{n \cdot C_{\mathrm{e}} \Phi \cdot V(t)}{n \cdot R_{\mathrm{TEM}}+R_{\mathrm{ish}}}\right] e^{-\frac{t}{\tau_{1}}}$,

where the time constant equals $\tau_{1}=\frac{n \cdot L_{\mathrm{TEM}}+L_{\mathrm{ish}}}{n \cdot R_{\mathrm{TEM}}+R_{\mathrm{ish}}}$.

While the current $i_{1}(t)$ is increasing, the TEMs is storing the electromagnetic energy during the period of closed controller Swl. After some time, the commutator Swl is opened so the total emf $E_{\text {gen }}(t)=n \cdot E_{\text {arm }}$ and the emf of self-induction $E_{L}(t)$ create the braking current in the loop 1-2-5-C- $R_{C}-\mathrm{Sw} 2-3-4-1$. This process is described by the next equation

$$
\begin{aligned}
& {\left[R_{\mathrm{add}}(t)+R_{\Sigma}\right] \cdot C \frac{d u_{C}}{d t}+u_{C}(t)=} \\
= & n \cdot C_{\mathrm{e}} \Phi \cdot\left(V_{\mathrm{fn} 1}(t)+\frac{d V}{d t} \cdot t\right)+E_{L}(t),
\end{aligned}
$$

where

$$
\begin{gathered}
E_{L}(t)=\left(n \cdot L_{\mathrm{TEM}}+L_{\mathrm{ish}}\right) \cdot\left[\frac{n \cdot C_{\mathrm{e}} \Phi}{n \cdot R_{\mathrm{TEM}}+R_{\mathrm{ish}}} \cdot \frac{d V}{d t}-\right. \\
-\frac{I_{02}}{\tau_{1}} \cdot e^{-\frac{t}{\tau_{1}}}+\frac{n \cdot C_{\mathrm{e}} \Phi}{n \cdot R_{\mathrm{TEM}}+R_{\mathrm{ish}}} \cdot \frac{V(t)}{\tau_{1}} \cdot e^{-\frac{t}{\tau_{1}}}- \\
\left.-\frac{n \cdot C_{\mathrm{e}} \Phi}{n \cdot R_{\mathrm{TEM}}+R_{\mathrm{ish}}} \cdot \frac{d V}{d t} \cdot e^{-\frac{t}{\tau_{1}}}\right]
\end{gathered}
$$

Solution of (12) allows to find the charging voltage $u_{C}(t)$ and charging current $i_{3}(t)=C \frac{d u_{C}}{d t}$.

In the next turning on of the controller Swl the TEMs are shorted again and the current $i_{1}(t)$ increases. After turning off of the controller Sw1 the current charges the SSS and cycle is repeated again. Such braking process reduces the speed $V$ and total TEMs' emf $E_{\text {gen }}$ in (10), therefore the duty cycle and the additional resistance $R_{\text {add }}$ have to be reduced to keep the barking current $I_{1}=$ const .

\section{Numerical calculations of charging process}

The initial data for numerical calculations were found by the experimental researches for the EPL2T multiple-unit train in the process of real operation in the sections of Prydniprovsk railway (Ukraine). All data were recorded using on-board control system and train was driven according standard schedule and driving chart. The motor car of the train has four DC motors of 1DT.003.L8U1 type, which are connected in series and have series excitation. Some parameters of TEM elements are shown in Table 1 [15].

The statistical and probability analyses are done to find the values of voltage, recovered energy, initial and final speeds of the regenerative braking mode and they are shown in Figs. 3-5. The calculations of the voltage across the SSS and the charging current are performed using the abovementioned equations (8)-(9), solution of (12) for a motor car of $3 \mathrm{kV}$ DC multiple-unit train and results of experimental researches. Let us analyse them and describe the selection of the initial data for numerical calculations.

The initial speed $V_{\text {in }}$ of regenerative braking varies in wide range with the mathematical expectation equals $72.1 \mathrm{~km} / \mathrm{h}$ in Fig. 3. Its theoretical curve has normal distribution, therefore this value may to be used in the numerical calculation as the most probably one.

Table 1. Main parameters of the parts of DC traction motor of 1DT.003.L8U1 type [15].

\begin{tabular}{|c|c|c|c|}
\hline \multirow{2}{*}{ Parts of TEM and their parameters } & \multicolumn{2}{c|}{$\begin{array}{c}\text { Values for the } \\
\text { exceed temperatures }\end{array}$} \\
\cline { 2 - 4 } & $+20^{\circ} \mathrm{C}$ & $+75^{\circ} \mathrm{C}$ \\
\hline \multirow{2}{*}{ Armature coil } & $R_{\mathrm{arm}}[\mathrm{Ohm}]$ & 0.052 & 0.068 \\
\cline { 2 - 4 } & $L_{\mathrm{arm}}[\mathrm{H}]$ & 0.0072 & 0.0072 \\
\hline \multirow{2}{*}{$\begin{array}{c}\text { Commutating } \\
\text { winding }\end{array}$} & $R_{\mathrm{cw}}[\mathrm{Ohm}]$ & 0.017 & 0.022 \\
\cline { 2 - 4 } & $L_{\mathrm{cw}}[\mathrm{H}]$ & 0.0033 & 0.0033 \\
\hline \multirow{2}{*}{$\begin{array}{c}\text { Field coil } \\
R_{\mathrm{fc}}[\mathrm{Ohm}]\end{array}$} & 0.097 & 0.127 \\
\hline \multirow{2}{*}{$\begin{array}{c}\text { Coil of inductive } \\
\text { shunt }\end{array}$} & $L_{\mathrm{fc}}[\mathrm{H}]$ & 0.014 & 0.014 \\
\cline { 2 - 4 } & $L_{\mathrm{ish}}[\mathrm{Ohm}]$ & 0.0306 & 0.04 \\
\hline
\end{tabular}

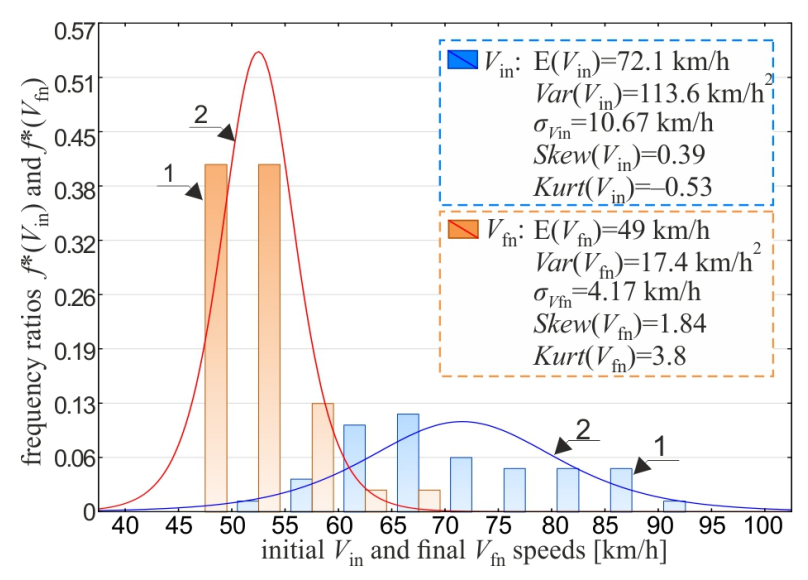

Fig. 3. Statistical (1) and theoretical (2) distributions of the initial and final speeds in the RBM.

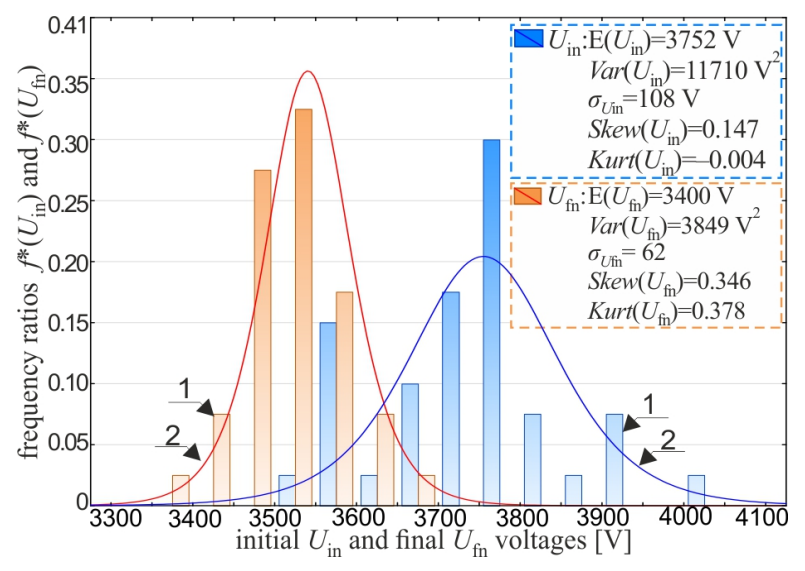

Fig. 4. Statistical (1) and theoretical (2) distributions of the initial and final voltages in the RBM. 


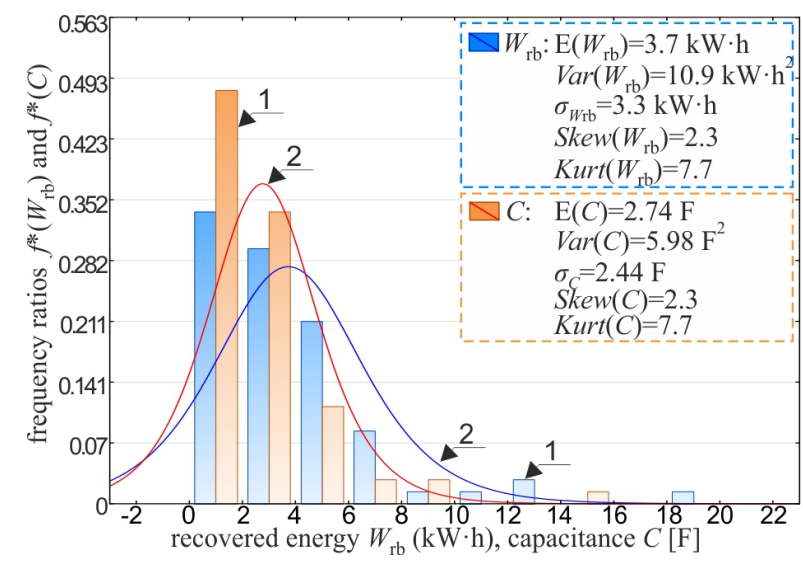

Fig. 5. Statistical (1) and theoretical (2) distributions of the energies recovered in different phases in the RBM and necessary capacities to store it.

The nominal voltage $U_{\text {Cnom }}$ of the SSS is one of the most significant quantities, which depends on the volume of recovered energy in a phase of RBM and influences on number of series-parallel cells and, as a result, on total capacitance and internal resistance of the SSS. According different reasons and researches, which are overview above in the paper, it is determined by the nominal voltage of current collector $(3 \mathrm{kV})$, or the nominal voltage of overhead contact system $(3.3 \mathrm{kV})$, or the open circuit voltage of traction substation $(3.6 \mathrm{kV})$, or the total nominal voltage of TEMs $(3.75 \mathrm{kV})$, or the maximal allowable voltage of TEMs $(3.95 \mathrm{kV})$. The statistical analysis presented in Fig. 4 shows that the voltage across the current collector of train in the initial and final moments of the RBM are varying within the range from 3.4 to $4.02 \mathrm{kV}$ with mathematical expectations equal $3.752 \mathrm{kV}$ and $3.4 \mathrm{kV}$ respectively. Both values are not distributed by the normal low, so the numerical calculations were performed for a few nominal voltages $(3.6,3.75$ and $3.95 \mathrm{kV})$ to find the most appropriate of them.

The nominal capacity $C$ of SSS is determined by the energy $W_{\mathrm{rb}}$, which is recovered in a phase of RBM. Fig. 5 shows the statistical and theoretical distributions of these values. The capacities here are calculated for each phase of RBM according the next formula:

$$
C=\frac{2 \cdot W_{\mathrm{rb}}}{U_{\text {Cnom }}^{2}-\left(0.5 \cdot U_{\text {Cnom }}\right)^{2}} .
$$

It is seen, that it has the mathematical expectation of $2.74 \mathrm{~F}$ for the voltage of $3.6 \mathrm{kV}$. As for as its theoretical distribution does not follow to the normal low, therefore it cannot be used as a nominal value. Capacitances for the SSS with nominal voltage of $3.6 \mathrm{kV}$ are $2.25,3$ and 4.5 F. Many companies produce the supercapacitors, for example: MAXWELL, YUNASKO, WIMA, Nesscap, SAMWHA, IOXUS, Cornell Dubilier et al. The YUNASKO supercapacitors were used in calculations and their parameters are given in [16].

The residual voltages of SSS are equal to 25, 50 and $75 \%$ of the nominal voltage $U_{C \text { nom }}$.

The additional resistance is calculated as $R_{\text {add }}(t)=8.1-0.685 \cdot t \quad(\mathrm{Ohm})$ and is necessary to restrict the charging current of SSS, but practically is used only $2 \div 8$ seconds of the first stage of RBM.

Fig. 6. shows of main time dependences of total TEMs' emf $E(t)$, the voltage of SSS $u_{C}(t)$, the charging current $i_{1}(t)$ and the speed $V(t)$ only for case when $C=3 \mathrm{~F}$ and $U_{C \text { nom }}=3600 \mathrm{~V}$.
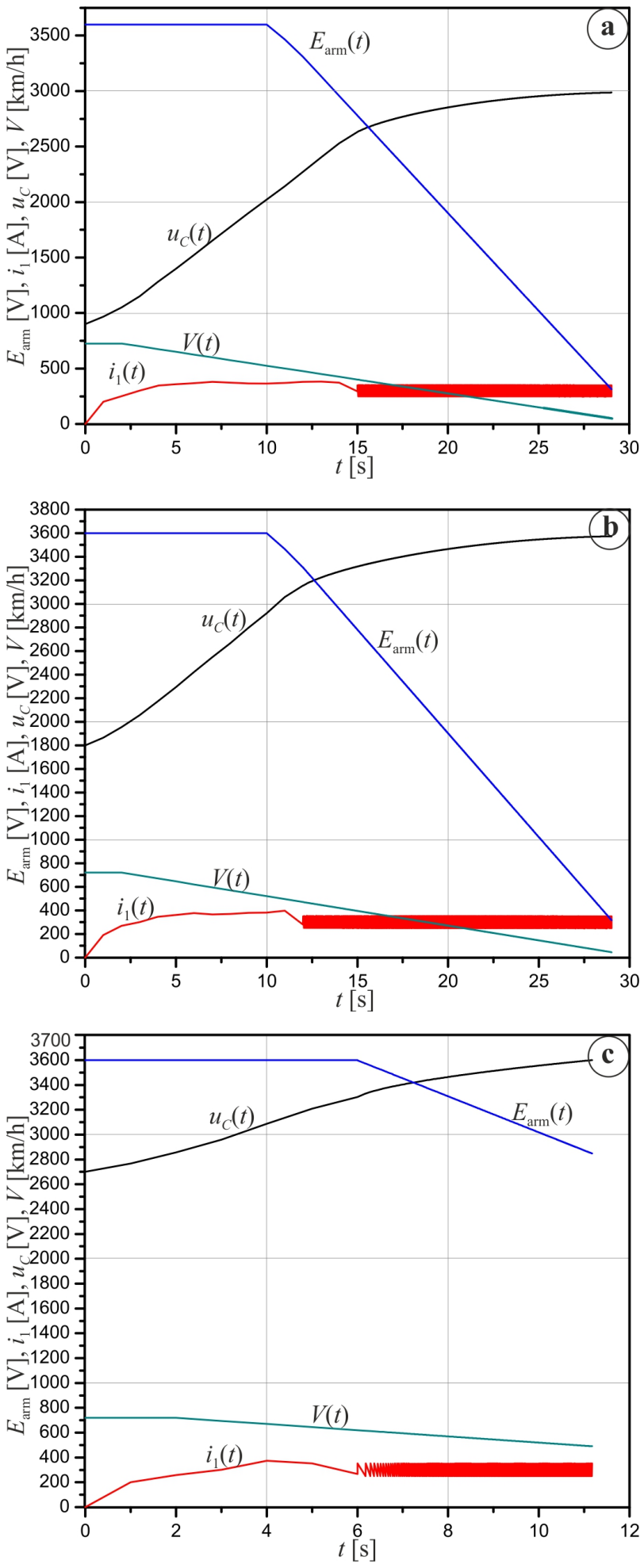

Fig. 6. Results of numerical calculations for $C=3 \mathrm{~F}$, $U_{C \text { nom }}=3.6 \mathrm{kV}$ and different residual voltages: (a) $25 \%$, (b) $50 \%$ and (c) $75 \%$ of $U_{C \text { nom }}$. 


\section{Conclusions}

The regenerative braking mode of ERS with the serieswound DC traction motor may to be performed in two stages with the use of energy storage system. It is seen from the results, that the capacitor of $3 \mathrm{~F}$ with residual voltage of $50 \%$ is suitable in comparison with all other cases. In this case, the speed changes with the rage of $72 \div 51 \mathrm{~km} / \mathrm{h}$ and voltage of SSS increases from 1.8 to $3.15 \mathrm{kV}$. The second stage (impulse mode) is operable in the all cases and allows to finish charging till the SSS's voltage of $3.57 \mathrm{kV}$ and train's speed of $5 \mathrm{~km} / \mathrm{h}$. The calculated time dependences of the total emf, the voltage of SSS and the charging current look as authentic thus the mathematical models are applicable and scheme is operable for practical application.

The research was financed under the Dean's Grant no 504/03412/1041/42.000100 from the statutory activities of the Faculty of Electrical Engineering of Warsaw University of Technology.

\section{References}

1. A. Szeląg, L. Mierzejewski, J. Altus and J. Drabek, Railway electric traction in new EU members of Central and East European countries, Proceedings of $7^{\text {th }}$ International Scientific Conference "Modern Electric Traction in Integrated XXIst Century Europe" MET'2005, Warsaw, Poland, 192-205, (2005)

2. M. Kostin and A. Nikitenko, Recuperative braking autonomy is a basis of reliable and efficient energy recuperation in DC electric rolling stock, Railway Transport of Ukraine, 3(106), 15-23, (2014) [in Russian]

3. A. Szelag, M. Kostin and A. Nikitenko, Losses of recovered electric energy in the elements of a DC electric transport system, Proceeding of Power Electronics and Motion Control Conference (PEMC), 2016 IEEE International, Varna, Bulgaria, 412-418 (2016)

4. J. Morand, D. Bergogne, P. Venet, A. Sari and P. Bevilacqua, An energy saver for tramway networks using double active bridge and supercapacitors, Proceeding of 15th European Conference on Power Electronics and Applications, Lille, France, 1-9 (2013)

5. M. Bartołomiejczyk and M. Połom, Possibilities of reducing of energy consumption in urban transport on example of Gdynia Trolleybus Transportation System [Możliwości ograniczenia zużycia energii $w$ transporcie miejskim na przykładzie gdyńskiej komunikacji trolejbusowej], Railway Vehicles [Pojazdy Szynowe], 3, 86-88 (2011) [in Polish]

6. A. Del Pizzo, L. Fratelli and D. Perna, A method for "design to range" energy storage systems in catenary free operations of light railway vehicles, Proceeding of 2015 International Conference on Clean Electrical Power (ICCEP), Taormina, Italy, 761-766, (2015)

7. D. Iannuzzi, Improvement of the energy recovery of traction electric drives using supercapacitors, Proceeding of 13th International Power Electronics and Motion Control Conference EPE-PEMC, Poznań, Poland, 1469-1474 (2008)

8. M. Steiner and J. Scholten, Energy storage on board of DC fed railway vehicles, Proceeding of 35th IEEE Power Electronics Specialists Conference PESC, Aachen, Germany, 666-671 (2004)

9. L. Streit and P. Drabek, Simulation and emulation of tram with on-board supercapacitors on Pilsen tram line, Proceeding of International Conference on Clean Electric Power, Alghero, Czech Republic, 703-706 (2013)

10. Z. Giziński et al., Power supply circuits or traction vehicles with energy storages [Zasobnikowe uktady zasilania $w$ pojazdach trakcyjnych], Railway Vehicles [Pojazdy szynowy], 3, 125-133 (2011) [in Polish]

11. V. Bražis and J. Greivulis, The application of supercapacitor energy storage devices in DC drives, Proceedings of 7th International Scientific Conference "Engineering for Rural Development", Jelgava, Latvia, 76-80 (2008)

12. L. Latkovskis and V. Bražis, Simulation of the regenerative energy storage with supercapacitors in Tatra T3A type trams, Proceeding of 10th International Conference on Computer Modelling and Simulation, Cambridge, United Kingdom, 398403, (2008)

13 Y. Xiao et al., Regenerative braking of series-wound brushed DC electric motors for electric vehicles, Proceeding of 7th IEEE Conference on Industrial Electronics and Applications ICIEA, Singapore, 1658-1662 (2012)

14. M. Kostin and O. Sheikina, Theory of Electrical Engineering, Part 2, (Pub. Dep. of Dnipropetrovsk National University of Railway transport, Dnipropetrovsk 2007) [in Ukrainian]

15. H. Basov and S. Yatsko, Progress of Electric Multiple-Unit Rolling Stock, Part 2, (Apeks+, Kharkiv 2005) [in Ukrainian]

16. YUNASKO Ltd. EDLC Product: 3000 F E-cell, (2016) http://yunasko.com/images/data/YUNASKO_Datas heet_cell_3000F_E.pdf 